pISSN : 1979-0694

\title{
SISTEM DETEKSI OBJEK DENGAN MENGGUNAKAN SENSOR ULTRASONIK BERBASIS FUZZY
}

\author{
Elisawati \\ Sekolah Tinggi Manajemen Informatika dan Komputer (STMIK) Dumai \\ Jln. Utama Karya Bukit Batrem Dumai-Riau Kode Pos 28811 \\ elisa.wati@yahoo.com
}

\begin{abstract}
ABSTRAK
Sistem pendeteksi objek adalah alat yang digunakan untuk mendeteksi jarak objek yang ada di hadapan pengguna. Alat ini menggunakan Sensor ultrasonik DT-SENSE yang digunakan untuk mendeteksi jarak. Sensor ini mengirimkan lebar pulsa bervariasi dari 115 uS sampai 18,5 mS ke mikrokontroler yang berguna untuk mengukur jarak objek, sinyal tersebut di pantulkan ke objek dan akan diterima kembali oleh bagian penerima ultrasonik. Jarak yang bisa dibaca oleh sensor mulai dari $2 \mathrm{~cm}$ sampai $300 \mathrm{~cm}$. sedang mikrokontroler yang digunakan adalah Atmel 89S51 yang berguna untuk menerima lebar pulsa yang dikirimkan dari sensor ultrasonik serta mengontrol logika fuzzy dan mengontrol IC suara information storage device (ISD) 2590. Logika fuzzy dimasukkan ke dalam DT-51 adalah jarak dekat, sedang dan jauh pada posisi jarak yang telah ditentukan. Software yang di gunakan untuk membuat logika fuzzy adalah PetraFuz51. Output untuk alat ini menggunakan IC suara ISD 2590 yang berguna untuk memberikan informasi lewat speaker apa yang terdeteksi oleh sensor. Pengujian dilakukan dengan menjalankan alat deteksi objek dengan mengukur jarak output yang dihasilkan dan jarak output tersebut dibandingkan dengan data aktual yang sebenarnya sehingga di dapat tingkat error dari alat tersebut sebesar 0.05\%. maka dapat disimpulkan bahwa alat deteksi ini bisa bekerja dengan baik dan dapat di gunakan bagi pengguna yang memerlukan kebutuhan khusus seperti tuna netra.
\end{abstract}

Kata Kunci : Deteksi Objek, Sensor Ultrasonik, Logika fuzzy

\section{PENDAHULUAN}

\subsection{Latar Belakang}

Pada tahun 1965 pelopor pada bidang fuzzy lotfi A. Zadeh, seorang profesor dari Universitas Of California di Berkeley, menulis paper tentang teori himpunan fuzzy dan menyampaikan salah satu tujuan dari teorinya adalah untuk membuat "mesin yang pandai".

Sri Kusuma Dewi (2006) menambahkan bahwa logika fuzzy adalah suatu cara yang tepat untuk memetakan suatu ruang input ke dalam suatu ruang output. Teori himpunan fuzzy merupakan kerangka matematis yang digunakan untuk mempresentasikan ketidaktpastian, ketidakjelasan, ketidaktepatan, kekurangan informasi dan kebenaran parsial. Masalah ketepatan, dan ketidakpastian bisa disebabkan oleh beberapa hal, seperti informasi yang tidak dapat dihitung, informasi yang tidak lengkap, maka beberapa penelitian menggunakan metode fuzzy mulai banyak dilakukan, dan terbukti memiliki kinerja yang sangat baik.

Aplikasi pada teknologi fuzzy secara pokok ada dua kategori, pertama aplikasi fuzzy pada sistem kontrol, aplikasi sistem akan lebih mudah dan efesien dengan menggunakan basis data fuzzy, seperti pada sistem auto focus pada kamera, sensor, mesin cuci, transmisi otomatis atau untuk pengaturan kereta api di bawah tanah. Pada aplikasi seperti ini logika fuzzy digunakan sebagai teknik penyajian kembali pengetahuan secara mantap yang mengijinkan penggunaan data yang kurang lengkap dan untuk menangani data yang tidak jelas atau kabur.

Berdasarkan hal diatas, penulis mencoba untuk menerapkan metode fuzzy ke dalam sensor ultrasonik yang berguna untuk dapat mendeteksi objek yang dihadapan pengguna dengan mengkategorikan jarak yang termasuk dekat, sedang dan jauh. Karena alasan-alasan di atas, maka dengan ini penulis tertarik melakukan penelitian ini yang berjudul "Sistem Deteksi Objek Dengan Menggunakan Sensor Ultrasonik Berbasis Fuzzy".

\subsection{Tujuan Penelitian}

Tujuan dilakukan penelitian ini adalah Untuk mempelajari metode logika fuzzy, sensor ultrasonik dan mikrokontroler AT89S51 serta alat deteksi ini dapat digunakan oleh pengguna yang memerlukan kebutuhan khusus seperti tuna netra. 
I N F O R M A T I K

Jurnal Informatika, Manajemen dan Komputer, Vol. 9 No. 1, Mei 2017

eISSN : 2580-3042

pISSN : 1979-0694

\subsection{Tinjauan pustaka}

\section{A. Sensor Ultrasonik}

Sensor ultrasonik adalah sensor yang bekerja berdasarkan prinsip pantulan gelombang suara, di mana sensor menghasilkan gelombang suara yang kemudian menangkapnya kembali dengan perbedaan waktu sebagai dasar pengindraannya. Perbedaan waktu antara gelombang suara yang dipancarkan dan yang di terima kembali adalah berbanding lurus dengan jarak atau tinggi objek yang memantulkannya. Sensor ini dapat mengukur $2 \mathrm{~cm}$ sampai $300 \mathrm{~cm}$. keluaran dari sensor DT-SENSE berupa pulsa yang lebarnya merepresentasikan jarak. Lebar pulsanya bervariasi dari $115 \mathrm{uS}$ sampai $18,5 \mathrm{mS}$.

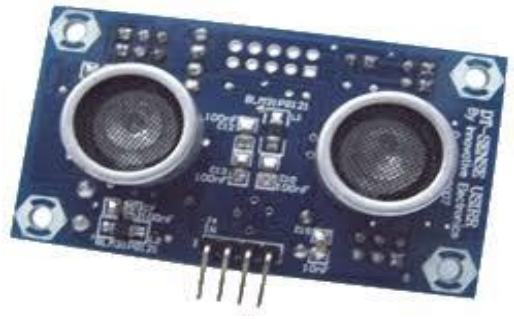

Gambar 1. Sensor Ultrasonik DT-SENSE

\section{B. DT-51 Minimum System Petrafuz}

DT-51 merupakan minimum sistem berbasis mikrokontroler yang di desain oleh Innovative Electrics. Mikrokontroler ini kompatibel penuh dengan mikrokontroler 8031. DT-51 minimum system Petrafuz ini berguna untuk program logika Fuzzy.

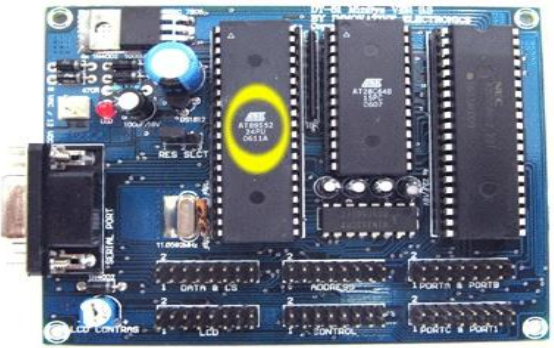

Gambar 2. DT-51 Minimum System Petrafuz

\section{Logika Fuzzy}

Logika fuzzy pertama kali diperkenalkan oleh Lutfi Zadeh pada pertengahan tahun 1960 di Universitas California Barkeley. Logika ini di ciptakan karena Boolean logic tidak mempunyai ketelitian yang tinggi, hanya mempunyai logika 0 dan 1 saja, sehingga untuk membuat sistem yang mempunyai ketelitian yang tinggi maka kita tidak dapat menggunakan Boolean logic. Sedangkan logika fuzzy merupakan sebuah logika yang memiliki nilai kekaburan atau kesamaran (fuzzyness) antara benar dan salah. Dalam teori logika fuzzy sebuah nilai bisa bernilai benar dan salah secara bersamaan namun berapa besar kebenaran dan kesalahan suatu nilai tergantung kepada bobot keanggotaan yang dimilikinya. (Kusumadewi Sri, Purnomo Hari, 2010)

\section{Metode Penelitian}

\section{A. Kerangka penelitian}

Kerangka penelitian yang di gunakan dalam penelitian ini adalah sebagai berikut :

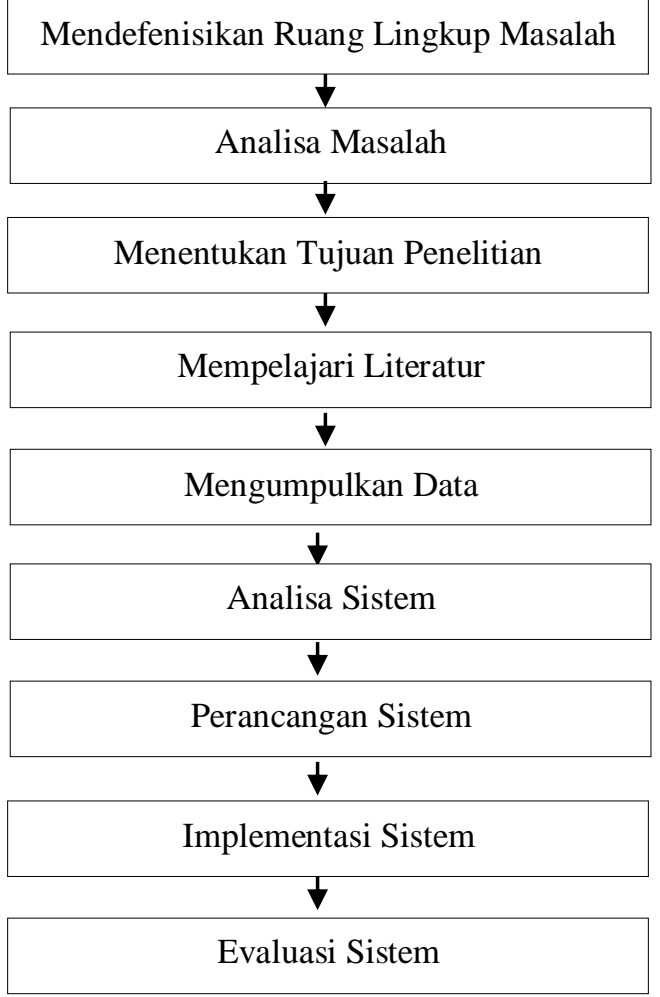

\section{B. Diagram Blok Perancangan Sistem}

Diagram blok perancangan sistem implementasi yang akan dilakukan pada penelitian ini dapat dilihat pada gambar 3 .

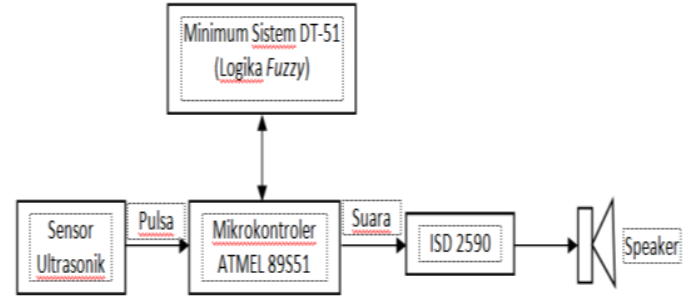

Gambar 3. Diagram Blok Sistem

Deskripsi pada gambar 3 adalah sebagai berikut :

1. Sensor ultrasonik digunakan untuk mendeteksi jarak. Dalam hal ini sensor DTSENSE mengirimkan lebar pulsa bervariasi dari $115 \mathrm{uS}$ sampai $18,5 \mathrm{mS}$ ke mikrokontroler yang berguna untuk mengukur jarak objek dalam $\mathrm{cm}$. sinyal tersebut 
dipantulkan ke objek dan akan di terima kembali oleh bagian penerima ultrasonik. Jarak yang di baca oleh sensor adalah mulai dari $2 \mathrm{~cm}-300 \mathrm{~cm}$.

2. Mikrokontroler yang digunakan adalah ATMEL 89S51, yang berguna untuk menerima lebar pulsa yang dikirimkan dari sensor ultrasonik dan mengontrol logika fuzzy serta mengontrol IC suara ISD 2590.

3. IC information storage device (ISD) 2590 durasi 90 detik di gunakan untuk memberikan informasi berupa suara lewat speaker apa yang terdeteksi oleh sensor.

4. Minimum Sistem DT-51 yang berguna untuk logika fuzzy. Logika fuzzy yang akan dimasukkan ke dalam DT-51 adalah jarak dekat, sedang dan jauh pada posisi jarak yang telah di tentukan. Software yang di gunakan untuk membuat logika fuzzy adalah PetraFuz51.

\section{Rancangan Alat Deteksi Objek}

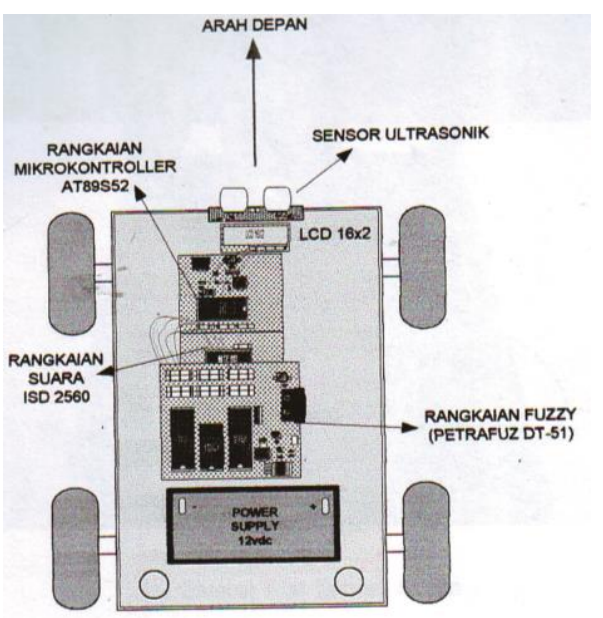

Gambar 4. Rancangan Alat Deteksi Objek

\section{HASIL DAN PEMBAHASAN}

Hasil pengujian yaitu untuk mengetahui hasil dari perangkat keras, perangkat lunak dan system Fuzzy yang telah dilakukan pengujian. Adapun hasil pengujian yang dilakukan adalah sebagai perikut :

\section{A. Perangkat Keras}

\section{Mikrokontroler}

Pengujian dilakukan dengan menjalankan program mikrokontroler tersebut, jika lampu LED yang dipasang hidup secara bergantian maka mikrokontroler berjalan dengan normal. Dapat dilihat pada tabel 1 hasil pengujian dari mikrokontroler sebagai berikut :
Tabel 1. Hasil Pengujian Mikrokontroler

\begin{tabular}{|c|c|c|c|c|c|c|c|c|c|}
\hline \multirow{2}{*}{ Port } & Data & \multicolumn{9}{|c|}{ Output Port (Kondisi LED) } \\
\cline { 3 - 10 } & Port & 7 & 6 & 5 & 4 & 3 & 2 & 1 & 0 \\
\hline 0 & $00 \mathrm{H}$ & 0 & 0 & 0 & 0 & 0 & 0 & 0 & 0 \\
\hline 0 & FFH & x & X & x & x & x & X & x & x \\
\hline 1 & $00 \mathrm{H}$ & 0 & 0 & 0 & 0 & 0 & 0 & 0 & 0 \\
\hline 1 & FFH & x & X & x & x & x & X & x & x \\
\hline 2 & $00 H$ & 0 & 0 & 0 & 0 & 0 & 0 & 0 & 0 \\
\hline 2 & FFH & x & X & x & x & x & X & x & x \\
\hline 3 & $00 H$ & 0 & 0 & 0 & 0 & 0 & 0 & 0 & 0 \\
\hline 3 & FFH & x & X & x & x & x & X & x & x \\
\hline
\end{tabular}

Ket :

- Jika data port bernilai 00H maka lampu LED dinyatakan padam/mati.

- Jika data port bernilai FFH maka lampu LED di nyatakan hidup

\section{IC Information Storage Device (ISD) 2590}

Pengujin dilakukan dengan menjalankan program IC suara ISD tersebut, jika output suara mengeluarkan kata depan dekat, depan sedang, dan depan jauh sesuai yang di rekam maka IC suara ISD berjalan dengan normal. hasil pengujian dari information storage device (ISD) dapat dilihat ditabel 2 sebagai berikut :

Tabel 2. Hasil Pengujian IC ISD 2590

\begin{tabular}{|c|c|c|c|c|c|c|c|c|c|c|}
\hline \multirow{2}{*}{ No } & \multicolumn{9}{|c|}{ Port ISD (A1 - A9) } & \multirow{2}{*}{$\begin{array}{l}\text { Ouput } \\
\text { Suara }\end{array}$} \\
\hline & 9 & 8 & 7 & 6 & 5 & 4 & 3 & 2 & 1 & \\
\hline 1 & 0 & 0 & 0 & 0 & 0 & 0 & 0 & 0 & 0 & Dekat \\
\hline 2 & 0 & 1 & 1 & 0 & 1 & 1 & 0 & 0 & 0 & Sedang \\
\hline 3 & 0 & 0 & 0 & 0 & 1 & 1 & 0 & 0 & 0 & Jauh \\
\hline
\end{tabular}

\section{Sensor DT-SENSE}

Pengujian dilakukan dengan menjalankan program sensor ultrasonik DT-SENSE tersebut dan di ukur jarak output yang dihasilkan. Kemudian jarak output tersebut dibandingkan dengan data aktual yang sebenarnya. Hasil pengujian dari sensor DT-SENSE dapat dilihat ditabel 3 sebagai berikut :

Tabel 3. Hasil Pengujian DT-SENSE

\begin{tabular}{|c|c|c|c|}
\hline $\begin{array}{c}\text { Jarak } \\
(\mathrm{cm})\end{array}$ & $\begin{array}{c}\text { Ouput } \\
\text { Sensor } \\
\text { Ultrasonik } \\
(\mathrm{cm})\end{array}$ & $\begin{array}{c}\text { Aktual } \\
\text { yang } \\
\text { sebenarnya } \\
(\mathrm{cm})\end{array}$ & $\begin{array}{c}\text { Error } \\
(\%)\end{array}$ \\
\hline 2 & 0.00 & 0.00 & 0 \\
\hline 10 & 10.00 & 10.00 & 0 \\
\hline 20 & 20.00 & 20.00 & 0 \\
\hline 30 & 30.00 & 30.00 & 0 \\
\hline 40 & 41.00 & 40.00 & 0.01 \\
\hline
\end{tabular}


INFORMA TIK

Jurnal Informatika, Manajemen dan Komputer, Vol. 9 No. 1, Mei 2017

eISSN : 2580-3042

pISSN : 1979-0694

\begin{tabular}{|c|c|c|c|}
\hline 50 & 51.00 & 50.00 & 0.01 \\
\hline 60 & 61.00 & 60.00 & 0.01 \\
\hline 70 & 70.00 & 70.00 & 0 \\
\hline 80 & 80.00 & 80.00 & 0 \\
\hline 90 & 91.00 & 90.00 & 0.01 \\
\hline 100 & 101.00 & 100.00 & 0.01 \\
\hline 200 & 200.00 & 200.00 & 0 \\
\hline 300 & 300.00 & 300.00 & 0 \\
\hline \multicolumn{3}{|c|}{ Total Error } & $0.05 \%$ \\
\hline
\end{tabular}

Dari tabel di atas dapat dilihat bahwa error dari output sensor ultrasonik hanya $0.05 \%$ kesalahan, sehingga dapat disimpulkan bahwa sensor ultrasonik dapat bekerja dengan baik sesuai dengan data aktual yang sebenarnya.

\section{B. Perangkat Lunak}

Pengujian dilakukan dengan menjalankan sistem deteksi keseluruhan. Dapat dilihat tabel 4 hasil pengujian dari sistem deteksi sebagai berikut :

Tabel 4. Hasil pengujian sistem deteksi

\begin{tabular}{|c|c|}
\hline $\begin{array}{c}\text { Benda dalam } \\
\text { jarak }(\mathrm{cm})\end{array}$ & $\begin{array}{c}\text { Output IC } \\
\text { Suara ISD 2590 }\end{array}$ \\
\hline 5 & Dekat \\
\hline 10 & Dekat \\
\hline 20 & Dekat \\
\hline 30 & Dekat \\
\hline 40 & Dekat \\
\hline 50 & Dekat \\
\hline 60 & Dekat \\
\hline 70 & Sedang \\
\hline 80 & Sedang \\
\hline 90 & Sedang \\
\hline 100 & Jauh \\
\hline
\end{tabular}

Kemudian dilakukan pengujian objek yang mana saja yang bisa terdeteksi oleh sensor ultrasonik adalah sebagai berikut :

Tabel 5. Pengujian Objek berdasarkan jenisnya

\begin{tabular}{|c|l|l|}
\hline No & \multicolumn{1}{|c|}{$\begin{array}{c}\text { Jenis } \\
\text { Objek }\end{array}$} & \multicolumn{1}{c|}{ Pengujian } \\
\hline 1 & Kayu & Terdeteksi \\
\hline 2 & Kertas & Terdeteksi \\
\hline 3 & Plastik & Terdeteksi \\
\hline 4 & Baju & $\begin{array}{l}\text { Terdeteksi (Tergantung } \\
\text { Ketebalan kain) }\end{array}$ \\
\hline 5 & Besi & Terdeteksi \\
\hline 6 & Kardus & Terdeteksi \\
\hline 7 & Kaca & Terdeteksi \\
\hline 8 & Batu & Terdeteksi \\
\hline 9. & Manusia & Terdeteksi \\
\hline
\end{tabular}

Kemudian untuk ketinggian objek dilakukan pengujian berapa centimeter yang bisa terdeteksi oleh sensor ultrasonik sebagai berikut:

Tabel 6. Pengujian Tinggi Objek

\begin{tabular}{|l|l|l|}
\hline No & \multicolumn{1}{|c|}{$\begin{array}{c}\text { Ketinggian Objek } \\
(\mathrm{cm})\end{array}$} & \multicolumn{1}{|c|}{ Pengujian } \\
\hline 1 & $0-8$ & $\begin{array}{l}\text { Tidak } \\
\text { Terdeteksi }\end{array}$ \\
\hline 2 & $9-19$ & Terdeteksi \\
\hline 3 & $20-$ seterusnya & $\begin{array}{l}\text { Tidak } \\
\text { Terdeteksi }\end{array}$ \\
\hline
\end{tabular}

Dari tabel di atas dapat dilihat bahwa ketinggian objek yang bisa terdeteksi oleh sensor ultrasonik adalah $9-19 \mathrm{~cm}$.

\section{Hasil Gambar Keseluruhan Alat Deteksi Objek}

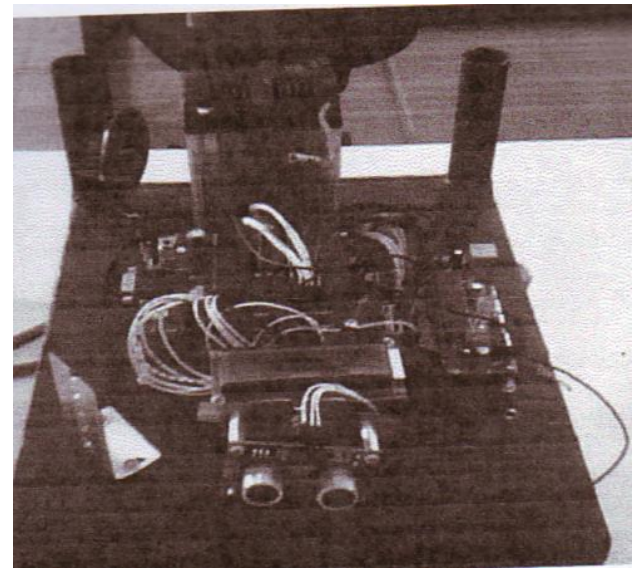

Gambar 5. Alat Deteksi Objek

\section{KESIMPULAN}

Dari hasil penelitian yang lakukan dapat disimpulkan dari analisa diantaranya sebagai berikut:

1. Metode fuzzy dapat membantu proses pengambilan keputusan dihadapan pengguna yaitu dengan memberikan crisp input dekat, sedang, dan jauh pada sistem objek. Maka output fuzzy yang di dapat akan mengkategorikan objek yang mana termasuk dekat, sedang, dan jauh sehingga pengguna dapat mengetahui jarak objek yang ada di hadapannya.

2. Pada saat sensor mendeteksi objek yang ada di hadapan pengguna, mikrokontroler akan menerima jarak yang di kirimkan dari sensor dan mikrokontroler akan mengirimkan jarak tersebut ke minimum DT-51 yang sudah dimasukkan sistem 
IN F ORMA T I K

Jurnal Informatika, Manajemen dan Komputer, Vol. 9 No. 1, Mei 2017

eISSN : 2580-3042

pISSN : 1979-0694

Fuzzy, sehingga IC suara ISD akan mengeluarkan output dalam bentuk suara apakah jarak yang diterima termasuk dekat, sedang dan jauh. Maka dari itu dapat dilakukan bahwa metode fuzzy dapat membantu dalam proses pengambilan keputusan.

3. Mikrokontroler bisa terintegrasi dengan komponen lainnya dengan menghubungkan port-port dan memberikan sistem kendali pada mikrokontroler sehingga mikrokontroler dapat mengontrol dan terintegrasi dengan sensor DT-SENSE, IC ISD 2590 dan minimum DT-51 (System Fuzzy).

\section{REFERENSI}

Budiharto Widodo, Firmansyah Sigit. (2008). Elektronika Digital + Mikroprosesor. Yogyakarta : Andi.

Dhuzell Dhany. Artikel Modul Ping (Parallax Ultrasonic).

Kusumadewi Sri. (2002). Analisa Desain Sistem Fuzzy Menggunakan Tool Box Matlab. Yogyakarta : Graha Ilmu

Kusumadewi Sri, Purnomo Hari. (2010). Aplikasi Logika Fuzzy untuk Pendukung Keputusan Edisi 2. Yogyakarta : Graha Ilmu.

Kusumadewi Sri, Hartati Sri, Harjoko Agus, Wardoyo Retantyo. (2006). Fuzzy MultiAtribute Decesion Making (Fuzzy $M A D M)$. Yogyakarta : Graha Ilmu

Naba Agus. (2009). Belajar Cepat Fuzzy Logic Menggunakan Matlab. Yogyakarta : Andi.

Setiawan Sulhan. (2006). Mudah dan menyenangkan belajar mikrokontroler. Yogyakarta : Andi.

Zarkasi Ahmad. (2009). Jurnal Robot Avoider dengan Sistem Fuzzy Logic Menggunakan dua sensor Ultrasonik dengan kendali MCU AT89C51 dan PIC16F84.

www.yakuzanet.wordpress.com. (2010). Sensor ultrasonik dan mikrokontroler.

www.iddhien.com. (2005 - 2010). Artikel dasardasar pemahaman logika fuzzy.

www.datasheetarchive.com. Datasheet Sensor DT-SENSE

www.datasheetarchive.com. Datasheet ISD 2590.

www.datasheetarchive.com.Datasheet

Mikrokontroler MCS-51. 